Type of Article: Mini Review

\title{
Title: EXPLORING URGENT NON-PHARMACOLOGICAL AND SOCIOECONOMIC INTERVENTIONS FOR THE COVID 19 EPIDEMIC IN SPAIN.
}

Running title: Non-pharmacological interventions for COVID 19

\section{Authors and affiliations:}

1. Jose Manuel Rojo-Manaute, MD, PhD1. Corresponding author. Mailing address: MedCare Orthopaedics \& Spine Hospital, 2nd Interchange, Sheikh Zayed Road, P. O. Box 215565, Dubai, United Arab Emirates.; E-mail: jose.manuel@medcarehospital.com.

2. Alberto Capa-Grasa, $\mathrm{MD}, \mathrm{PhD}^{2}$.

3. Guillermo Rodriguez-Maruri, $\mathrm{MD}, \mathrm{PhD}^{3}$

4. Francisco Chana-Rodríguez, MD, $\mathrm{PhD}^{4}$.

5. Pedro Puerta Zaballa, MSc, PMP-R 5 .

6. Pablo Diaz Freire, $\mathrm{MD}^{6}$.

1 Unit of Hand Surgery. Department of Orthopaedics. Medcare Orthopaedics \& Spine Hospital. Dubai, UAE. E-mail: jose.manuel@medcarehospital.com

2 Department of Physical and Rehabilitation Medicine. University Hospital La Paz. Madrid, Spain.

${ }^{3}$ Department of Family Medicine. Primary Care Health Centre El Coto. Asturias, Spain.

${ }^{4}$ Department of Orthopaedic Surgery. University Hospital Gregorio Marañón. Madrid, Spain.

${ }^{5}$ Mechanical Engineer at ESTI Bilbao/ MSc Thermal Power / Project Manager, Professional Credential \#2020885.

${ }^{6}$ Department of Orthopaedic Surgery. University Hospital La Paz. Madrid, Spain.

Conflicts of interest: none. 


\begin{abstract}
English
Non-pharmacological interventions in the fight against COVID 19 include: a) suppression, which facilitates its extinction; and b) mitigation, which reduces its speed of spread. Left unmitigated, the intensive care unit bed capacity (ICU) is exceeded over its maximum supply, resulting in increased deaths. Suppression has shown in simulation models the potential for decreasing ICU occupation below its surge limit, effectively decreasing mortality. However, for avoiding a rebound in transmission, suppression must be maintained intermittently until a vaccine is available (which may take up to 2 years). The objective of this paper was to describe the mortality patterns observed in Spain, Italy and South Korea for discussing a hypothetical combined public health policy and socioeconomic model that could potentially reduce mortality while reducing the economic impact of this pandemic in Spain. The plan is based on a progressive-voluntary reinstatement to work of the population exposed to the lowest risks (healthy non-immune family units $<50 \mathrm{y} / \mathrm{o}$ and immune population) and it depends on having sufficiently available ICU beds for providing adequate support. This model, if proven correct for Spain, could eventually be followed by other countries facing a similar impact of the present pandemic.
\end{abstract}

\title{
Keywords
}

Non-pharmacological interventions; COVID 19; health policy; mortality; economic; intensive care unit.

\section{Abbreviations}

NPI: non-pharmacological interventions; GB: Great Britain; US: United States of America; ICU: intensive care unit; Case fatality ratio (CFR).

\section{Funding}

This research did not receive any specific grant from funding agencies in the public, commercial, or not-for-profit sectors. 


\section{Introduction}

There are two fundamental non-pharmacological interventions (NPI) in the fight against the COVID 19 pandemic $^{1}$ : a) suppression, which attempts to reverse epidemic growth below a level that facilitates its extinction; and b) mitigation, which attempts to reduce the speed of spread of the outbreak without extinguishing it. In a simulation model done at the Imperial College, Ferguson et $\mathrm{al}^{1}$ compared the results from an unmitigated strategy (avoiding any NPI) versus the implementation of mitigation (case isolation, household quarantine and social distancing of the elderly) versus a suppressive strategy (social distancing of the entire population, case isolation, household quarantine and school and university closure) in Great Britain (GB) and in the United States of America (US).

In an unmitigated epidemic scenario, Ferguson et $\mathrm{al}^{1}$ estimated that $81 \%$ of the population would be infected over the course of the epidemic and that the intensive care unit bed capacity (ICU) would be exceeded in GB by a demand over 30 times greater than its maximum bed supply, resulting in approximately 510,000 deaths in the GB and 2.2 million in the US. In a mitigated scenario, they expected that the surge limits for ICU beds would be exceeded by at least 8-fold, resulting in 250,000 deaths for GB and 1.1 to 1.2 million in the US. Suppression showed the potential for decreasing ICU occupation below its surge limit, resulting in their best strategy for decreasing mortality. However, for avoiding a rebound in transmission, suppression would be maintained for at least $66 \%$ of the time until a vaccine was available for immunizing the population - which could take 1.5 to 2 years ${ }^{1}$. Thus, suppression would require an "on / off" implementation, so that the entire population would be allowed to return to work (maintaining mitigation measures) each time the number of ICU weekly admission rates decreased below a value ("off" mechanism); whereas the entire population would be re-suppressed each time the ICU admission rate exceeded a value ("on"). The application of this method would generate "contained epidemic waves" until the entire population acquired immunity (possibly after around $80 \%$ of the population had been infected or vaccinated) ${ }^{1}$.

The population of Spain, Italy and South Korea is fairly close in size (46.7, 51.2 and 60.5 million, respectively) ${ }^{2}$; however, these countries had shown different mortality rates during this pandemic at the time at which this manuscript was written (April 16 ${ }^{\text {th }}, 2020$ ). Case fatality ratios (CFR) and total deaths had been much higher in Spain and Italy ${ }^{3-5}$. The objective of this paper was to describe the mortality patterns observed in Spain, Italy and South Korea for discussing a hypothetical combined public health policy and socioeconomic model that could potentially reduce mortality while reducing the economic impact of this pandemic in Spain.

\section{Discussion}

\section{Methods applied in this review.}

We descriptively studied the number of deceased patients, the number of confirmed infected cases and CFR (deaths due to coronavirus/ number of confirmed cases), based on the latest available data by age range published by the Ministries of Health of Spain ${ }^{4}$, Italy ${ }^{5}$ and South Korea ${ }^{3}$ on April $15^{\text {th }}, 2020$ (Table 1). These countries were chosen for being well developed countries, with a population relatively similar in size to Spain but with different CFRs.

The true proportion of the total population infected in the country (attack rate) was estimated for Spain on March $28^{\text {th }}$ by the Imperial College ${ }^{6}$ suggesting that, cumulatively, 7,040,195 people had been infected, giving an average attack rate of $15.0 \%$ of the population. Based on this attack rate and on the CFR reported on March 28 ${ }^{\text {th }}$ in Spain ${ }^{7}$ (Table 2), we estimated the death rate that would have occurred in a hypothetical scenario where the entire Spanish population $<50 \mathrm{y} / \mathrm{o}$ would have become infected after being allowed to restart work unsuppressed on March $28^{\text {th }}$, while the rest of the population $(>50 \mathrm{y} / \mathrm{o})$ was kept under suppression.

2. Description of the mortality patterns observed in Spain, Italy and South Korea. 
The data published on April $15^{\text {th }}$ at the Spanish Ministry of Health ${ }^{4}$, showed an overall $10.46 \%$ CFR. Data for age groups (Table 1) showed a $0.43 \%$ CFR (163 deaths in 37,498 cases) for patients younger than $50 \mathrm{y} / \mathrm{o}$. On April 15 ${ }^{\text {th }}, 2020$, the Korean Center for Disease Control and Prevention ${ }^{3}$, reported lower mortality rates than Spain, with a $2.12 \%$ CFR and a $0.065 \%$ CFR in patients $<50$ y/o (4 deaths in 6,135 cases). Italy had presented their statistics ${ }^{5}$ for the general population on April 9th, with mortality rates relatively similar to Spain: a $12.2 \%$ CFR and a $0.54 \%$ CFR in patients $<50 \mathrm{y} / \mathrm{o}$ (197 deaths in 36,431 cases). Italy had also described that their health workers had much lower mortality rates, with a $0.34 \%$ CFR for all ages and a $0.066 \%$ CFR for patients < 50 y/o (5 deaths in 7,568 cases) (Table 1).

3. Mortality rate estimation if we had allowed the Spanish population $<50 \mathrm{y} / \mathrm{o}$ becoming infected after March $28^{\text {th }}$ : hypothetical scenario.

On March $28^{\text {th }}$, the Spanish Ministry of Health ${ }^{7}$ had reported an overall $7.9 \%$ CFR and a $0.26 \%$ CFR in patients $<50 \mathrm{y} / \mathrm{o}$ (Table 2). Assuming a $15 \%$ attack rate, the true mean infection lethality rate for the population of the entire country was possibly around 8 deaths per 10,000 infected cases $\left(5,690\right.$ total reported deaths in 7,040,195 mean estimated infections). Furthermore, on March $28^{\text {th }}$, only $2.15 \%$ of the deceased patients were $<50 \mathrm{y} / \mathrm{o}$ ( 31 deaths $<50 \mathrm{y} / \mathrm{o}$ out of 1,442 total deaths); thus, by extrapolating this data, the approximate true infection lethality rate in patients $<50 \mathrm{y} / \mathrm{o}$ in the entire country would have been around 0.29 deaths per 10,000 cases $(2.15 \%$ of the 5,690 total deaths over the 7,040,195 estimated infections reported in the country), which is a mortality rate 46 times lower than for the general population (Table 2). Therefore, for our hypothetical scenario, where the entire Spanish population $<50$ y/o would have become infected after being left unsuppressed, 815 patients would have been expected to die.

4. Importance of CFR and true infection lethality rates in patients $<50 \mathrm{y} / \mathrm{o}$ : implications for health policies.

Following Ferguson's model ${ }^{1}$, decreasing ICU occupation below its surge limit, should result in the best strategy for decreasing mortality. In the following weeks after this manuscript was written, we expected to see Spain decreasing its ICU occupation below its surge limit ${ }^{8}$. Moreover, there was an intense ongoing debate for deciding how to implement further NPI. If we followed Ferguson's model ${ }^{1}$, we risked inducing "contained epidemic" waves by applying an "on and off" suppression strategy to our entire society for up to 2 years. Each wave could increase mortality if ICU occupation raised above surge limit, and it could severely affect the economy.

There are some causes of death at an epidemic scale in our world that do not trigger suppression strategies. Road traffic accidents have been considered by the World Health Organization as a hidden global epidemic ${ }^{9}$, and the 2018 motor-vehicle death rate in the US was 1.42 per 10,000 vehicles ${ }^{10}$ on the road per year $(0.014 \%)$. The CFR for Hepatitis A in adults ${ }^{11}$ is around $1,8 \%$, and the CFR for Influenza $\mathrm{A}^{12}$ is somewhere around $0.1 \%$. Despite this data, vaccination for Hepatitis A and Influenza A is not compulsory in most countries in the European Union ${ }^{13}$. Moreover, despite the previous death rates in the previous epidemic conditions, the population circulates by road vehicle freely, and no suppressive measures are routinely implemented for those infectious diseases. In Spain and Italy, the CFR for patients $<50 \mathrm{y} / \mathrm{o}$ has been $<0.55 \%$, which is lower than the one for Hepatitis A in adults. Furthermore, the Italian working-population in the health sector (potentially exposed to the highest viral loads) have shown a CFR $<0.1 \%$ for patients $<50 \mathrm{y} / \mathrm{o}$, which is similar to the one for Influenza A (Table 1).

Flaxman et $\mathrm{al}^{6}$, in a study analyzing the impact of NPI in 11 European countries, estimated that there are orders of magnitude fewer infections detected than true infections, mostly likely due to mild and asymptomatic infections as well as limited testing capacity. For Spain, Flaxman ${ }^{6}$ estimated an average attack rate of $15.0 \%$. Based on his data, we believe that the true overall lethality rate for the entire Spanish population could possibly be much lower $(8$ per 10,000$)$ than its CFR $(10.46 \%)$. Moreover, for the population $<50 \mathrm{y} / \mathrm{o}$, we could be facing a lower true lethality rate $(0.29$ per 10,000$)$ than the annual mortality rate derived from driving a car in the US. This mortality rate would be 45.5 times lower than the expected true overall lethality rate in our population $>50 \mathrm{y} / \mathrm{o}$, if left exposed to the infection (Table 2). Furthermore, based on the Italian 
experience in their health workers, we should also hypothesize that the true lethality rate should be much lower in the healthy actively working population.

The Spanish population under 50 y/o currently represents $59.34 \%{ }^{14}$ of the entire country's population, and it comprises $74 \%$ of the population under $65 \mathrm{y} / \mathrm{o}$ (which includes the working age population). Based on our discussion, we hypothesize (Figure 1) that a selective suppression of the population should further reduce the number of deaths and lessen the impact on the economy if, when having enough ICU beds available for our population:

1. We allowed the healthy non-immune family units with all members $<50$ y/o to return voluntarily to their work (or studies) under mitigating conditions for achieving herd immunity (without no longer suppressing them again). We would define "healthy patients" as the ones without risk factors ${ }^{15}$ for developing a lethal from of infection (e.g.: diabetes, hypertension, cardiovascular disease, chronic respiratory disease, cancer, immunodepression and pregnancy). Further studies should detail these risk factors.

2. We allowed all the immune family units to return voluntarily to their normal daily activities under mitigating conditions (without no longer suppressing them again). The methods for determining immunity would depend on technology that should be deployed in the coming weeks (e.g. IgG detection).

3. Our state provided support to family units that had some non-immune members $\geq 50 \mathrm{y} / \mathrm{o}$ and/or unhealthy, but whose other members $(<50 \mathrm{y} / \mathrm{o}$, healthy, immune) were fit for voluntarily returning to work. Hotels, residences or duly qualified media could temporarily house these members at risk.

4. We allowed age ranges $\geq 50 \mathrm{y} / \mathrm{o}$ to return voluntarily to work, once we had achieved sufficiently safe herd immunity (e.g. 80\%) for the population under $50 \mathrm{y} / \mathrm{o}^{1}$.

5. We maintained suppressive measures in the population that did not match the above indications.

Under Ferguson's model ${ }^{1}$, we would basically be exposing the entire population to the virus every time that the suppression is "off", which could translate into having epidemic waves with a $2.12 \%$ CFR (Korea) to $12.2 \%$ CFR (Italy). Moreover, under Ferguson's model ${ }^{1}$, we would only allow full working conditions for $33 \%$ of time in the 24 months following the first epidemic peak (due to multiple re-suppressions). On the other hand, by selectively unsuppressing the population $<50 \mathrm{y} / \mathrm{o}$, our model could witness an expected number of deaths up to 46 times lower than the one derived from exposing the entire population to the virus, and it could allow up to around $80 \%$ of our work force to resume work full-time (with no re-suppressions) once our ICU occupation dropped below its surge capacity and we had sufficient ICU beds for supporting our population at risk (possibly, in days or weeks after this manuscript was written).

\section{Conclusions}

Based on our analysis of the existing literature, we propose a combined public health and socioeconomic model that could theoretically seek to provide our decision makers in Spain with alternative tools to the ones that are being implemented at present for: quickly achieving immunity with the lowest possible mortality, while propping up the fall of our economy. The plan is based on a progressive-voluntary reinstatement to work of the population exposed to the lowest risks (healthy non-immune family units $<50 \mathrm{y} / \mathrm{o}$ and immune population) and it depends on having sufficiently available ICU beds for providing adequate support. This model, if proven correct for Spain, could eventually be followed by other countries facing a similar impact of the present pandemic. 


\section{References.}

1. Ferguson N, Laydon D, Nedjati-Gilani G. Impact of non-pharmaceutical interventions (NPIs) to reduce COVID19 mortality and healthcare demand. Imperial College COVID-19 Response Team [Internet]. Available from: https://doi.org/10.25561/77482.

2. World Population Prospects: The 2019 Revision [database on the Internet]. United Nations Population Division. [cited June 17, 2019]. Available from: https://data.un.org/Data.aspx?d=PopDiv\&f=variableID\%3a12\%3btimeID\%3a83\%2c84\%3bvarI D\%3a2\&c=2,4,6,7\&s=_crEngNameOrderBy:asc,_timeEngNameOrderBy:desc,_varEngNameOrder By:asc\&v=1\#PopDiv.

3. The updates on COVID-19 in Korea as of 15 April. Korea Center for Disease Control and Prevention; [updated April 15, 2020]; Available from: https://www.cdc.go.kr/board/board.es?mid=a30402000000\&bid=0030\&act=view\&list_no=366 892\&tag $=\&$ nPage $=1$.

4. Actualización no 76. Enfermedad por el coronavirus (COVID-19). Ministerio de Sanidad, Consumo y Bienestar Social. Gobierno de España; [updated April 15, 2020]; Available from: https://www.mscbs.gob.es/en/profesionales/saludPublica/ccayes/alertasActual/nCovChina/documentos/Actualizacion_76_COVID-19.pdf.

5. Epidemia COVID-19. Aggiornamento nazionale. 9 aprile 2020. Task force COVID-19 del Dipartimento Malattie Infettive e Servizio di Informatica ISdS. Istituto Superiore di Sanità; [updated April 10, 2020]; Available from: https://www.epicentro.iss.it/coronavirus/bollettino/Bollettino-sorveglianza-integrata-COVID19_9-aprile-2020.pdf.

6. Flaxman S, Mishra S, Gandy A. Report 13 - Estimating the number of infections and the impact of non-pharmaceutical interventions on COVID-19 in 11 European countries. Available from: https://www.imperial.ac.uk/media/imperial-college/medicine/mrc-gida/2020-03-30COVID19-Report-13.pdf.

7. Actualización no 58. Enfermedad por el coronavirus (COVID-19). Ministerio de Sanidad, Consumo y Bienestar Social. Gobierno de España; [updated March 28, 2020]; Available from: https://www.mscbs.gob.es/en/profesionales/saludPublica/ccayes/alertasActual/nCovChina/documentos/Actualizacion_58_COVID-19.pdf.

8. Zafra M, Blanco PR, Pires LS. Casos confirmados de coronavirus en España y en el mundo. El País (newspaper); Available https://elpais.com/sociedad/2020/04/09/actualidad/1586437657_937910.html.

9. Chapter 6: Neglected Global Epidemics: three growing threats. World Health Organization; Available from: https://www.who.int/whr/2003/chapter6/en/index3.html.

10. Motor-vehicle Fatality Trends. National Safety Council; Available from: https://injuryfacts.nsc.org/motor-vehicle/historical-fatality-trends/deaths-and-rates.

11. Hamborsky J, Kroger A, Wolfe S. Epidemiology and Prevention of Vaccine-Preventable Diseases. Chapter: Hepatitis A. Center for Disease Control and Prevention.13th ed. Washington D.C. Public Health Foundation, 2015. Available from: https://www.cdc.gov/vaccines/pubs/pinkbook/hepa.html.

12. Wong JY, Kelly H, Ip DK, Wu JT, Leung GM, Cowling BJ. Case fatality risk of influenza A (H1N1pdm09): a systematic review. Epidemiology. 2013;24(6):830-41. Epub 2013/09/21.

13. Haverkate M, D'Ancona F, Giambi C, Johansen K, Lopalco PL, Cozza V, et al. Mandatory and recommended vaccination in the EU, Iceland and Norway: results of the VENICE 2010 survey on the ways of implementing national vaccination programmes. Euro surveillance : bulletin Europeen sur les maladies transmissibles = European communicable disease bulletin. 2012;17(22). Epub 2012/06/13.

14. Instituto Nacional de Estadística [database on the Internet]. Ministerio de Asuntos Económicos y Transformación Digital. [cited Jul 1, 2019]. Available from: https://www.ine.es/jaxiT3/Tabla.htm?t=31304.

15. Enfermedad por coronavirus, COVID-19. Actualización; 17 de abril 2020. Ministerio de Sanidad, Consumo y Bienestar Social. [updated April 17, 2020]; Available from: https://www.mscbs.gob.es/profesionales/saludPublica/ccayes/alertasActual/nCov-

China/documentos/20200417_ITCoronavirus.pdf. 
Tables.

\begin{tabular}{|c|c|c|c|c|c|c|c|c|c|c|c|c|c|}
\hline & & \multicolumn{3}{|c|}{ Spain, April 15 ${ }^{\text {th }}$} & \multicolumn{3}{|c|}{ South Korea, April 15 } & \multicolumn{3}{|c|}{$\begin{array}{c}\text { Italy, general population, } \\
\text { April 9th }\end{array}$} & \multicolumn{3}{|c|}{$\begin{array}{c}\text { Italy, health workers, } \\
\text { April 9th }\end{array}$} \\
\hline & & $\begin{array}{c}\text { Deceased } \\
\text { patients }\end{array}$ & $\begin{array}{l}\text { Confirmed } \\
\text { Infected } \\
\text { cases }\end{array}$ & CFR & $\begin{array}{c}\text { Deceased } \\
\text { patients }\end{array}$ & $\begin{array}{l}\text { Confirmed } \\
\text { Infected } \\
\text { cases }\end{array}$ & CFR & $\begin{array}{c}\text { Deceased } \\
\text { patients }\end{array}$ & $\begin{array}{c}\text { Confirmed } \\
\text { Infected } \\
\text { cases }\end{array}$ & CFR & $\begin{array}{c}\text { Deceased } \\
\text { patients }\end{array}$ & $\begin{array}{l}\text { Confirmed } \\
\text { Infected } \\
\text { cases }\end{array}$ & CFR \\
\hline \multicolumn{2}{|c|}{ Total } & 18,579 & 177,633 & $10.46 \%$ & 225 & 10,591 & $2.12 \%$ & 16,654 & 136,110 & 12,2 & 48 & 14,032 & $0.34 \%$ \\
\hline \multirow{11}{*}{ Age } & 0 to 9 & 1 & 382 & $0.26 \%$ & 0 & 132 & $0.00 \%$ & 1 & 938 & $0.11 \%$ & & & \\
\hline & 10 to 19 & 1 & 682 & $0.15 \%$ & 0 & 569 & $0.00 \%$ & 0 & 1,432 & $0.00 \%$ & & & \\
\hline & 20 to $29 *$ & 17 & 6294 & $0.27 \%$ & 0 & 2,895 & $0.00 \%$ & 7 & 6,360 & $0.11 \%$ & 0 & 1,284 & $0.00 \%$ \\
\hline & 30 to 39 & 35 & 11752 & $0.30 \%$ & 1 & 1,131 & $0.09 \%$ & 36 & 9,956 & $0.36 \%$ & 2 & 2,346 & $0.09 \%$ \\
\hline & 40 to 49 & 109 & 18388 & $0.59 \%$ & 3 & 1,408 & $0.21 \%$ & 153 & 17,745 & $0.86 \%$ & 3 & 3,938 & $0.08 \%$ \\
\hline & 50 to 59 & 284 & 22844 & $1.24 \%$ & 14 & 1,937 & $0.72 \%$ & 638 & 26,391 & $2.42 \%$ & 14 & 4,809 & $0.29 \%$ \\
\hline & 60 to 69 & 887 & 20137 & $4.40 \%$ & 33 & 1,339 & $2.46 \%$ & 1,957 & 21,734 & $9.00 \%$ & 20 & 1,568 & $1.28 \%$ \\
\hline & 70 to 79 & 2633 & 19042 & $13.83 \%$ & 68 & 702 & $9.69 \%$ & 5,366 & 22,934 & $23.40 \%$ & 9 & 87 & $10.34 \%$ \\
\hline & 80 to 89 & 4016 & 16962 & $23.68 \%$ & \multirow{2}{*}{106} & \multirow{2}{*}{478} & \multirow{2}{*}{$22.18 \%$} & 6,711 & 21,636 & $31.02 \%$ & & & \\
\hline & $90+$ & 1622 & 6335 & $25.60 \%$ & & & & 1,784 & 6,842 & $26.07 \%$ & & & \\
\hline & Sub-totals & 9,605 & 122,818 & $7.8 \%$ & 225 & 10,591 & $2.12 \%$ & 16,653 & 135,968 & $12.2 \%$ & 48 & 14,032 & $0.34 \%$ \\
\hline
\end{tabular}

Table 1. Case fatality ratio (CFR) distribution by age groups in the general population for Spain, South Korea and Italy. CFR = deceased patients / confirmed infected cases. *For the population of health workers in Italy, the lower age range studied was 18 to $29 \mathrm{y} / \mathrm{o}$. 


\begin{tabular}{|c|c|c|c|c|c|c|c|}
\hline & & \multicolumn{3}{|c|}{ Spain, Ministry of Health, March $28^{\text {th }}$} & \multicolumn{2}{|c|}{$\begin{array}{l}\text { True estimates for a } 15 \% \text { attack } \\
\text { rate, March } 28^{\text {th }}\end{array}$} & \multirow{2}{*}{$\begin{array}{c}\text { Expected deaths if entire } \\
\text { country became infected } \\
\text { Deaths (n) }\end{array}$} \\
\hline & & $\begin{array}{c}\text { Deceased } \\
\text { patients } \\
\text { n (\%) }\end{array}$ & $\begin{array}{c}\text { Confirmed } \\
\text { Infected cases }\end{array}$ & CFR & Infections (n) & Lethality /10,000 & \\
\hline \multicolumn{2}{|c|}{ Total } & $5,690(100 \%)$ & 72,248 & $7.9 \%$ & $7,040,195$ & 8.08 & 37,933 \\
\hline \multirow{3}{*}{ Age } & 0 to 49 & $31(2.15 \%)$ & 11,916 & $0.26 \%$ & $4,181,876$ & 0.29 & 815 \\
\hline & 50 to $90+$ & $1,411(97.8 \%)$ & 24,289 & $5.80 \%$ & $2,858,319$ & 19.48 & 37118 \\
\hline & Sub-totals & $1,442(100 \%)$ & 36,205 & $4 \%$ & & & \\
\hline
\end{tabular}

Table 2. Estimation of the true number of infections and true lethality rate / 10,000 population, for Spain on March $28^{\text {th}}$; and expected number of deaths if the entire country had become infected with our ICU occupation above its surge capacity. Data is calculated for a $15 \%$ attack rate, based on the data provided by the Spanish Ministry of Health on March $28^{\text {th }}$. Population for Spain in 2019 was 46,934,632 $(59.4 \%$ were $<50$ y/o). Case fatality ratio $(\mathrm{CFR})=$ deceased patients $/$ confirmed infected cases. 


\section{Figures.}

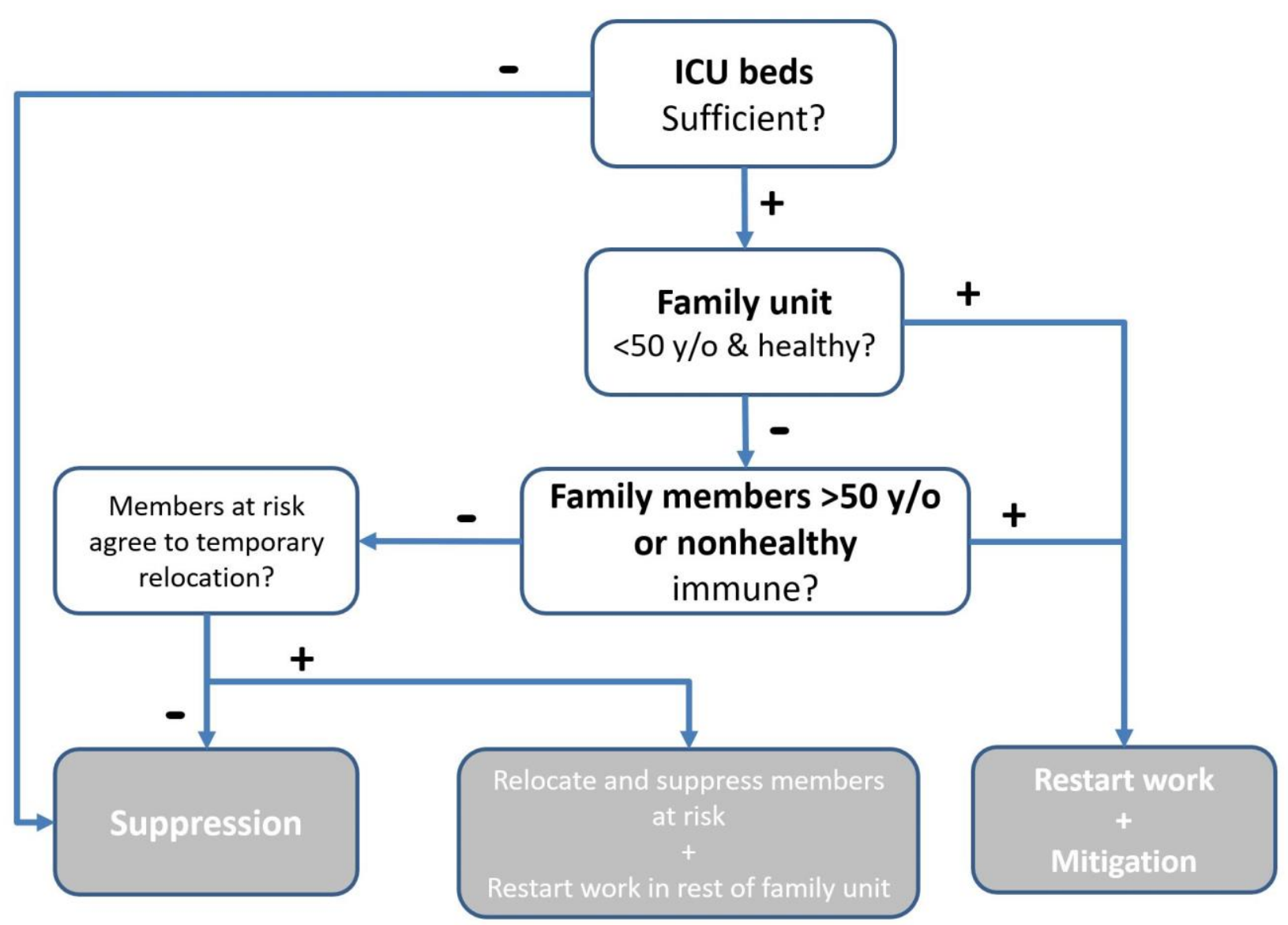

Figure 1. Flow diagram of a combined public health and socioeconomic model for policymakers for applying after the suppression of the first epidemic peak. The model would start its implementation when sufficient ICU beds were available (e.g.: 10 to $20 \%$ vacant). If all family members residing in the same location (family unit) were $<50 \mathrm{y} / \mathrm{o}$ and healthy, they could restart work under mitigation. If some family members were $>50$ y/o or were tagged as "unhealthy" (diabetes, hypertension, cardiovascular disease, chronic respiratory disease, cancer, immunodepression and pregnancy), they could restart work under mitigation if they were already immune (due to previous confirmed infection and/or to thru IgG tests). If the family unit agreed to temporarily relocate their members at risk in safe environments supervised by the state (e.g.: hotels, etc..), the rest of the family unit could restart work under mitigation. 